\title{
The Effect of Riboflavin Deficiency on Cerebrum and Cerebellum of Developing Rat Brain
}

\author{
A. J. Ogunleye and A. A. Odutuga \\ Department of Biochemistry, University of Ilorin, P. M. B. 1515, Ilorin, Nigeria
}

(Received September 29, 1988)

\begin{abstract}
Summary After 21-day-old weanling rats were maintained on diets deficient in riboflavin the weights of their brains were $19.8 \%$ less than those of rats on control diets. In riboflavin deficiency, the myelin lipids, cerebrosides, and sphingomyelin, as well as phosphatidylethanolamine, a significant component of the myelin membrane, were considerably reduced in proportion. It is considered that riboflavin plays some role in the metabolism of essential fatty acids in brain lipids and the pathological effect of its deficiency is similar to that of essential fatty acid deficiency, causing a fast impairment to brain development and maturation.
\end{abstract}

Key Words riboflavin, deficiency, lipids, brain and development

The role of riboflavin in the diet of animals has been reviewed by Foy and Mbaya(1). Lack of riboflavin manifests itself first by retardation and later by complete cessation of growth $(2,3)$. This vitamin is an integral part of the prosthetic group of acyl-CoA dehydrogenase (an enzyme of importance in the B-oxidation of fatty acids) and so a deficiency of this vitamin will affect the lipid content of organs such as the liver, kidney, adrenals, and arterial walls.

In mammals, the concentrations of brain lipids have been found to change in some dietary deficiencies (4-6). In rats, riboflavin deficiency has been associated with myelin degeneration(1). There is, however, a paucity of information on the effect of riboflavin deficiency on brain lipid composition. A study of the changes in the lipid composition of riboflavin-deficient cerebrum and cerebellum of rat brain has, therefore, been carried out.

\section{MATERIALS AND METHODS}

Forty male Wistar rats were divided into two groups each containing twenty animals and maintained respectively on the following diets: (1) riboflavin-deficient diet; and (2) control diet, containing adequate riboflavin.

The composition of the diets is shown in Table 1. The riboflavin-deficient diet contained no riboflavin. Riboflavin $(177.6 \mathrm{mg} / \mathrm{kg} \mathrm{diet})$ was added to the control diet. The animals were placed on the diet at 21 days of age and weighed weekly. Owing to high mortality in the deficient group, the experiment was terminated at 
Table 1. Composition of riboflavin-deficient diet.

\begin{tabular}{lc}
\hline Ingredient & $\frac{\mathrm{g} / \mathrm{kg} \text { Diet }}{516}$ \\
Corn starch & 250 \\
Casein (vitamin free) & 4 \\
DL-Methionine & 40 \\
Cellulose & 100 \\
Sucrose & 40 \\
Corn oil & 40 \\
Vitamin mix & 10 \\
Mineral mix $^{\mathrm{b}}$ & 1,000 \\
& \\
\hline
\end{tabular}

${ }^{a}$ The vitamin mixture supplied by Pfizer Livestock Feeds (Nig.) Ltd. contained the following ( $\mathrm{g} /$ per $\mathrm{kg})$ : ascorbic acid (1.0); choline chloride (1.665); calcium panthothenate (0.067); i-inositol (0.110); menadione (0.499); niacin (0.0999); $p$-amino benzoic acid (0.1110); pyridoxine-Hol (0.0222); thiamin (0.0222); biotin $(0.0004)$; folic acid (0.002); vitamin $\mathrm{B}_{12}(0.00003)$; vitamin A-acetate (0.02); $\mathrm{D}_{2}$-calciferol $(0.0022)$; and $\alpha$-tocopherol (0.614). ${ }^{\mathrm{b}}$ The composition of the mineral mixture prepared in the Biochemistry Department, University of Ilorin, was as follows $(\mathrm{g} / \mathrm{kg}): \mathrm{CaCO}_{3}, 6.45$; $\mathrm{CuSO}_{4} \cdot 5 \mathrm{H}_{2} \mathrm{O}, 0.00072$; ferric citrate, $0.64 ; \mathrm{MnSO}_{4} \cdot \mathrm{H}_{2} \mathrm{O}, 0.055 ;(\mathrm{COOK})_{2} \cdot \mathrm{H}_{2} \mathrm{O}, 9.46$; $\mathrm{KI}, 0.0016 ; \mathrm{NaCl}, 4.32 ; \mathrm{KH}_{2} \mathrm{PO}_{4}, 3.11 ; \mathrm{MgSO}_{4}, 1.13 ; \mathrm{CaHPO}_{4}, 14.22$ and $\mathrm{ZnCO}_{3}$, 0.0176; $\mathrm{Na}_{2} \mathrm{SeO}_{3}, 0.017 ; \mathrm{CoCl}_{2} \cdot 6 \mathrm{H}_{2} \mathrm{O}, 0.001$.

5 weeks.

The brains were removed, weighed and if lipids were not extracted immediately, they were stored for up to 6 days at $-20^{\circ} \mathrm{C}$. Dry weights, total lipids, lipid fractions and individual lipids were obtained as previously described (7-13). Analyses of variance were carried out to determine the statistical significance of results.

\section{RESULTS AND DISCUSSION}

Riboflavin-deficient animals exhibited pathological signs (such as hair, foot, and tail lesions) from the 12th day of the experiment. The body and brain weights of the pair-fed rats deficient in riboflavin were reduced to 65.6 and $88.2 \%$, respectively, of the control value (Table 2). Prentice and Bates(2) reported a considerably smaller increase in body weight than that observed in the present study for riboflavin-deficient rats. The differences in the results may partly be due to the type of rats used. They used male weanling Norwegian hooded rats while male Wistar rats were employed in the present study.

The higher ratio of brain to body weight observed in the deficiency state would probably indicate that the brain was more relatively spared than other organs. This observed quantitative protection of the brain is consistent with previous reports that the brain is normally protected from the effect of malnourishment imposed 
Table 2. Body and brain weights (g) of riboflavin-deficient rats.

\begin{tabular}{lcc}
\hline & \multicolumn{2}{c}{ Pair-fed } \\
\cline { 2 - 3 } Analysis & + Rib & - Rib \\
\hline Initial body wt. & $29.9 \pm 0.5$ & $30.5 \pm 0.7$ \\
Final body wt. & $165.4 \pm 5.8$ & $108.5 \pm 6.6$ \\
Brain weight & $6.20 \pm 0.3$ & $5.47 \pm 0.3$ \\
Ratio of brain/Final body wt. & $0.037 \pm 0.002$ & $0.050 \pm 0.003$ \\
\hline
\end{tabular}

The results are the mean values for ten rats in each group \pm SD.

Table 3. Lipids of rats brain cerebrum and cerbellum. Values are expressed as percentage dry weight and are the mean values from ten brains for each dietary group (analyzed in duplicate) \pm SD.

\begin{tabular}{|c|c|c|c|c|c|c|c|c|}
\hline & \multicolumn{8}{|c|}{ Anatomical region } \\
\hline & \multicolumn{4}{|c|}{ Cerebrum } & \multicolumn{4}{|c|}{ Cerebellum } \\
\hline & \multicolumn{2}{|c|}{$+\mathrm{Rib}$} & \multicolumn{2}{|c|}{- Rib } & \multicolumn{2}{|c|}{$+\mathrm{Rib}$} & \multicolumn{2}{|c|}{$-\mathrm{Rib}$} \\
\hline & Mean & SD & Mean & SD & Mean & SD & Mean & SD \\
\hline Total lipids & 51.2 & 3.7 & 49.5 & 2.9 & 47.3 & 2.4 & 47.8 & 2.9 \\
\hline Total phospholipid & 21.7 & 1.6 & 20.6 & 2.0 & 20.8 & 1.9 & 19.6 & 1.9 \\
\hline Phosphatidylcholine & 4.7 & 0.6 & 7.6 & 0.5 & 4.0 & 0.4 & 8.5 & 0.7 \\
\hline Sphingomyelin & 3.6 & 0.5 & 2.5 & 0.4 & 3.8 & 0.3 & 2.6 & 0.3 \\
\hline Phosphatidylethanolamine & 11.0 & 0.9 & 8.8 & 1.2 & 10.9 & 0.8 & 8.2 & 0.9 \\
\hline Phosphatidylserine & 0.7 & 0.1 & 0.8 & 0.1 & 0.5 & 0.1 & 0.5 & 0.1 \\
\hline Phosphatidylinositol & 0.7 & 0.1 & 0.7 & 0.1 & 0.4 & 0.04 & 0.7 & 0.1 \\
\hline Phosphatidic acid & 0.3 & 0.01 & 0.3 & 0.01 & 0.3 & 0.01 & 0.3 & 0.01 \\
\hline Diphosphatidylglycerol & 0.5 & 0.01 & 0.5 & 0.01 & 0.4 & 0.02 & 0.5 & 0.02 \\
\hline Total neutral lipids & 18.8 & 1.7 & 21.6 & 2.1 & 19.2 & 1.1 & 22.5 & 1.3 \\
\hline Free fatty acids & 1.1 & 0.1 & 7.2 & 0.4 & 0.9 & 0.1 & 6.8 & 0.5 \\
\hline Cerebrosides & 10.1 & 0.5 & 7.0 & 0.3 & 6.6 & 0.6 & 5.0 & 0.3 \\
\hline Gangliosides & 0.6 & 0.1 & 0.3 & 0.1 & 0.7 & 0.1 & 0.4 & 0.1 \\
\hline Dry weight (mg) & 329.4 & 18 & 241.2 & 11 & 76.6 & 5.5 & 67.8 & 4.0 \\
\hline Wet weight (mg) & 1,647 & 70 & 1,254 & 45 & 385 & 14 & 301 & 8.4 \\
\hline
\end{tabular}

after weaning in the rat $(6,14)$.

Results of the present study have shown that the total lipid concentration remained fairly constant (Table 3 ). Similarly, Odutuga (5) observed no change in total lipid concentration when rats were fed a diet deficient in essential fatty acids.

There were considerable changes in the concentration of the glycolipids in the deficiency state. Compared with the controls, when rats were fed riboflavin-deficient 
diet, cerebrosides were reduced to 69.3 and $75.8 \%$ in the brain cerebrum and cerebellum respectively. The values for gangliosides were 50 and $57.1 \%$ in the brain cerebrum and cerebellum, respectively. These values are statistically significant $(p<0.001)$. The cerebrosides and sphingomyelin are myelin lipids and have been used as an index of myelination(7). It has been observed in this study, that in riboflavin deficiency, there was a greater reduction in cerebral compared to cerebellar cerebrosides. This might indicate a slightly greater reduction in myelination. This difference in the effect of riboflavin deficiency on cerebrum as compared to cerebellum was not, however, as pronounced as that previously observed in EFA deficiency (6).

Phosphatidylcholine was significantly increased $(p<0.01)$ while phosphatidylethanoalmine was reduced $(p<0.01)$ when rats were fed riboflavin-deficient diet (Table 3). It has been suggested that phosphatidylcholine may have a role to play in non-myelin membrane formation during the early part of development (8). A considerable reduction ( 20.0 and $24.8 \%$ in cerebrum and cerebellum respectively), within 5 weeks, in the concentration of phosphatidylethanolamine, which is a major component of the myelin membrane, may indicate fast changes in membrane structures and function. Sphingomyelin, another myelin lipid, was significantly reduced to 69.4 and $68.4 \%(p<0.001)$ in cerebrum and cerebellum respectively when rats were maintained on riboflavin-deficient diet. Such a reduction has been previously reported for essential fatty acid deficiency (5).

The present study has clearly shown that there are interesting similarities between the pathology of essential fatty acid deficiency $(5,15)$ and riboflavin deficiency, particularly as regards brain composition. Foy and Mbaya ( 1 ) have suggested that the enormous increase in the size of liver mitochondria in riboflavin-deficient mice may be associated with diminished mitochondrial function. They also contended that the deficiency of essential fatty acids produced enlarged mitochondria which reverted to normal with riboflavin.

The accumulation of free fatty acids in both cerebrum and cerebellum observed in the present study would probably indicate inhibition of either lipolysis or prostaglandin synthesis. Moreover, the observed dermal lesions may indicate that essential fatty acids were not converted into prostaglandins in riboflavin deficiency. Similarly, it has been shown that prostaglandin synthesis in adipose tissue was increased by lipolytic hormones and reduced by essential fatty acid deficiency (16).

Since mitochondrial activities are associated with lipid metabolism, it is postulated that riboflavin is essential for phospholipid metabolism and the utilization of essential fatty acids. The altered lipid composition in riboflavin deficiency found in the present studies is considered to be a direct result of riboflavin deficiency $(17,18)$ affecting lipids, especially the essential fatty acids and phospholipids which are involved in the membrane structure metabolism, and altering the structure and function of brain cells and membranes $(5,19)$ and impairing the proper coupling of oxidative phosphorylation. 
The financial support of the University of Ilorin, Nigeria, through the Senate Research Grant is gratefully acknowledged.

\section{REFERENCES}

1) Foy, H., and Mbaya, V. (1977): Riboflavin Prog. Food Nutr. Sci., 2, 357-394.

2) Prentice, A. M., and Bates, C. J. (1981): A biochemical evaluation of the erythrocyte glutathione reductase [EC 1.6.4.2] test for riboflavin status. 1. Rate and specificity of response in acute deficiency. Br. J. Nutr., 112, 37-52.

3) Ogunleye, A. J. (1985): Effects of low dietary magnesium and riboflavin deficiency on development of rat brain. Nig. J. Sci., 19, 74-80.

4) Bettger, W. J., Reeves, P. G., Mascatelli, E. A., Reynolds, G., and O'Dell, B. L. (1979): Interaction of zinc and essential fatty acids in the rat. J. Nutr., 109, 480-488.

5) Odutuga, A. A. (1977): Recovery of brain from deficiency of essential fatty acids in rats and its effect on brain recovery. Biochem. Biophys. Acta, 481, 1-9.

6) Odutuga, A. A. (1982b): Effects of low-zinc status and essential fatty acid deficiency on growth and lipid composition of rat brain. Clin. Exp. Pharmacol. Physiol., 9, 213-221.

7) Dekaban, A. S., Patton, V. M., and Cain, D. F. (1971): Structural and biochemical maturation of the cerebral pallium in rabbit fetuses; Morphogenesis and lipids. $J$. Neurochem., 18, 2451-2459.

8) Odutuga, A. A., Carey, E. M., and Prout, R. E. S. (1973): Changes in the lipid and fatty acid composition of developing rabbit brain. Biochim. Biophys. Acta, 31, 115-123.

9) Folch, J., Lees, M., and Sloane-Stanley, G. H. (1957): A simple method for the isolation and purification of total lipids from animal tissues. J. Biol. Chem., 266, 497-509.

10) Amenta, J. S. (1964): A rapid chemical method for quantification of lipids separated by thin-layer chromatography. J. Lipid Res., 5, 270-272.

11) Renkonen, O., Gammberg, C. G., Simons, K., and Kaariainen, L. (1972): The lipids of the plasma membranes and endoplasmic reticulum from cultured baby hamster kidney cells (BH 21). Biochim. Biophys. Acta, 225, 66-78.

12) Prout, R. E. S., Odutuga, A. A., and Tring, F. C. (1973): Lipid analysis of rat enamel and dentine. Arch. Oral Biol., 18, 373-380.

13) Odutuga, A. A. (1981): Reversal of brain essential fatty acid deficiency in the rat by dietary linoleate, linolenate and arachidonate. Int. J. Biochem., 13, 1035-1038.

14) Culley, W. J., and Lineberger, R. O. (1968): Effect of undernutrition on the size and composition of the rat brain. J. Nutr., 96, 375-381.

15) Odutuga, A. A. (1979): Long-term deficiency of essential fatty acids in rats and its effect on brain recovery. Clin. Exp. Pharmacol. Physiol., 6, 361-366.

16) Martin, D. W., Jr., Mayes, P. A., and Rodwell, V. W. (1981): Harper's Review of Biochemistry. 18th edition. Lange Medical Publications, Los. Altos.

17) Biran, L. A., Bartley, W., Carter, C. W., and Renshaw, A. (1964): Studies on essential fatty acid deficiency: Effect of the deficiency on the lipids in various rat tissues and the influence of dietary supplementation with essential fatty acids on deficient rats. Biochem. J., 93, 492-498.

18) Bailey, E., Taylor, C. B., and Bartley, W. (1967): Turnover of mitochondrial components of normal and essential fatty acid deficient rats. Biochem. J., 104, 1026-1032.

19) Odutuga, A. A. (1982a): Effects of low-zinc status and essential fatty acid deficiency on bone development and mineralization. Comp. Biochem. Physiol., 71A, 383-388. 